Abstract\#: A-2021-RE10019

Tao Xingzhi Study Association of China \& Huzhou University

May 28-30, 2021, Huzhou, Zhejiang Province, China

\title{
Exploration and Implementation of the Construction of School Moral Education System Based
} on the Inheritance of Confucian Classics

\section{Weimin Qian}

Affiliation: Yuhuan Experimental Primary School, Taizhou 318000, Zhejiang, China

Address: Yuhuan Experimental Primary School, Taizhou 318000, Zhejiang, China

Correspondence to: Weimin Qian, E-mail: 785327606@qq.com

DOI: https://doi.org/10.15354/sief.21.s1.ab046

The authors declare no competing interest.

In the implementation of school moral education, as the lack of a well-developed system, the efficiency of moral education is relatively low which leads to the imperfect of the various functions. There is a pressing need to construct a moral system to guide and support the school moral education. By the chance of promotion "Confucius Cultural Theme School", our school integrated and systemized the existing moral education and then combined the Confucian moral education idea to formulate an education system for our school, which is the "young gentleman system". In the process of implementation, we promote moral education by theme activities and strengthen the students' upright moral quality and behavior through the practical activities, so as to accomplish the goal to foster a modest and self-disciplined gentleman.

\section{Keywords}

Confucian Classics, Young Gentlemen, Moral Education System, Theme Activities

Science Insights Education Frontiers, 2021 September 13; Vol. 10, Suppl. 1, pp.16.

(C) 2021 Insights Publisher. All rights reserved.

Creative Commons Non Commercial CC BY-NC: This article is distributed under the terms of the Creative Commons Attribution-NonCommercial 4.0 License which permits non-commercial use, reproduction and distribution of the work without further permission provided the original work is attributed by the Insights Publisher. 